\title{
PAPER
}

\section{Improvement of the Delany-Bazley and Miki models for fibrous sound-absorbing materials}

\author{
Takeshi Komatsu* \\ Industrial Research Institute of Shizuoka Prefecture, \\ 2078 Makigaya, Aoi-ku, Shizuoka, 421-1298 Japan \\ (Received 15 January 2007, Accepted for publication 23 July 2007)
}

\begin{abstract}
A new model for predicting the acoustical properties of fibrous materials, the characteristic impedance $Z c$ and the propagation constant $\gamma$, only from their airflow resistivity was constructed. The Delany-Bazley and Miki models are well known as conventional prediction methods. Their formulas are similar, and their difference is in the values of coefficients and degrees in the formulas. In this research, the acoustical properties and airflow resistivity of fibrous materials, 15 types of glass wool and 9 types of rock wool, were measured and compared with values obtained by conventional methods of prediction. It was found that the introduction of an expression involving the common logarithm improved the conventional models. This new model is more effective than the conventional models, particularly for the prediction for high-density fibrous materials where $f / \sigma<0.01 \mathrm{~m}^{3} / \mathrm{kg}$ and low-density ones where $f / \sigma>0.1 \mathrm{~m}^{3} / \mathrm{kg}$.
\end{abstract}

Keywords: Acoustical properties, Absorption coefficients, Characteristic impedance, Propagation constant, Fibrous materials

PACS number: 43.55.Ev [doi:10.1250/ast.29.121]

\section{INTRODUCTION}

Delany and Bazley, and Miki have presented expressions that predict the acoustical properties of porous soundabsorbing materials only from their airflow resistivity $[1,2]$. These expressions are widely applied to fibrous materials at present [3-5].

Delany and Bazley proposed expressions based on experimental data obtained from glass wool and rock wool. Miki amended the coefficients and degrees to satisfy the positive-real property of the real and imaginary parts of these expressions. It was in the 1960s that Delany and Bazley measured the data that were the basis for these two models. Since the 1980s, the use of Fast Fourier Transform (FFT) analysis has become wide spread. We are now able to perform a frequency analysis of the same experiment with high accuracy.

In this paper, the relationship between the airflow resistivity and the acoustical properties of glass wool and rock wool are discussed. Also, a new expression using the common logarithm that enables more precise prediction for fibrous material is proposed.

*e-mail: komatsu@iri.pref.shizuoka.jp

\section{PREDICTION EXPRESSIONS}

The acoustical properties of a porous sound-absorbing material, that is, the characteristic impedance $Z_{c}$ and the propagation constant $\gamma$, can be given as the complex expressions as follows:

$$
\begin{aligned}
& Z_{\mathrm{c}}=R+j X \\
& \gamma=\alpha+j \beta,
\end{aligned}
$$

where $R$ is the real component, $X$ is the imaginary component, $\alpha$ is the attenuation constant in nepers $/ \mathrm{m}$ ( 1 neper $\cong 8.686 \mathrm{~dB}), \beta=\omega / c$ is the phase constant in $\mathrm{rad} / \mathrm{m}, \omega$ is the angular frequency and $c$ is the speed of sound in the material.

\subsection{Delany-Bazley Model [1]}

In the Delany-Bazley model, $R$ and $X$ in Eq. (1) are expressed in the forms of Eqs. (3) and (4), and $\alpha$ and $\beta$ in Eq. (2) are expressed as Eqs. (5) and (6), where $\rho_{0}$ is the density of air, $c_{0}$ is the speed of sound in air, $f$ is the frequency, and $\sigma$ is the airflow resistivity. The coefficients of $(f / \sigma), a, c, p$ and $r$, and the degrees of $(f / \sigma), b, d, q$ and $s$, are shown in Table 1. 
Table 1 Coefficients and degrees of $(f / \sigma)$ in the Delany-Bazley model.

\begin{tabular}{lc}
\hline Coefficient & Degree \\
\hline$a=0.0497$ & $b=-0.754$ \\
$c=0.0758$ & $d=-0.732$ \\
$p=0.169$ & $q=-0.595$ \\
$r=0.0858$ & $s=-0.700$ \\
\hline
\end{tabular}

Table 2 Coefficients and degrees of $(f / \sigma)$ in the Miki model.

\begin{tabular}{lc}
\hline Coefficient & Degree \\
\hline$a=0.0699$ & $b=-0.632$ \\
$c=0.107$ & $d=-0.632$ \\
$p=0.160$ & $q=-0.618$ \\
$r=0.109$ & $s=-0.618$ \\
\hline
\end{tabular}

$$
\begin{aligned}
& R=\rho_{0} c_{0}\left\{1+a\left(\frac{f}{\sigma}\right)^{b}\right\} \\
& X=-\rho_{0} c_{0}\left\{c\left(\frac{f}{\sigma}\right)^{d}\right\} \\
& \alpha=\frac{\omega}{c_{0}} p\left(\frac{f}{\sigma}\right)^{q} \\
& \beta=\frac{\omega}{c_{0}}\left\{1+r\left(\frac{f}{\sigma}\right)^{s}\right\}
\end{aligned}
$$

\subsection{Miki Model [2]}

The Miki model has the same formula structure as Eqs. (3)-(6); however, the coefficients $(a, c, p$ and $r$ ) and the degrees $(b, d, q$ and $s)$ are different. They are shown in Table 2.

\section{MEASUREMENT TECHNIQUES}

Commercially available fibrous sound-absorbing materials, 15 types of glass wool (thickness $8-54 \mathrm{~mm}$ and bulk density $20-102 \mathrm{~kg} / \mathrm{m}^{3}$ ) and 9 types of rock wool (thickness $21-43 \mathrm{~mm}$ and bulk density $30-97 \mathrm{~kg} / \mathrm{m}^{3}$ ) were used as samples to determine the acoustical properties, $Z_{\mathrm{c}}$ and $\gamma$, and airflow resistivity, $\sigma$.

$Z_{\mathrm{c}}$ and $\gamma$ were measured in the frequency range from $100 \mathrm{~Hz}$ to $5 \mathrm{kHz}$ by the two-cavity method using a normalincidence acoustic impedance tube of $40 \mathrm{~mm}$ inner diameter, in accordance with the transfer-function method of ISO 10534-2 [6,7]. The separation of real and imaginary parts from the obtained $Z_{\mathrm{c}}$ and $\gamma$ gave the parameters, $R, X$, $\alpha$ and $\beta$, in Eqs. (3)-(6).

The airflow resistivity was measured by the direct airflow method of ISO 9053 [8]. The experimental apparatus is shown in Fig. 1. The internal diameter of

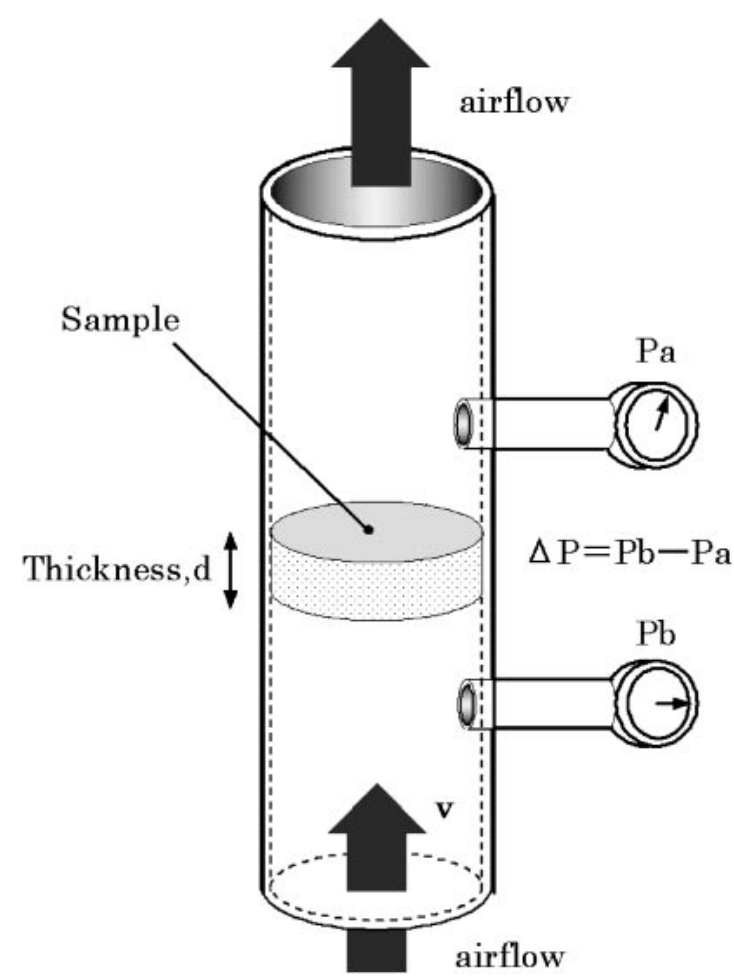

Fig. 1 Experimental apparatus used to measure airflow resistivity.

the cylinder tube is $40 \mathrm{~mm}$, so as to measure the same samples as those used in the measurement of acoustical properties.

\section{RESULTS AND DISCUSSION}

\subsection{Coefficients and Degrees in Conventional Predic- tion Models}

The measured airflow resistivity of the samples is shown in Table 3. The coefficients and degrees in Eqs. (3)(6) were determined on the basis of $R, X, \alpha$ and $\beta$, which were obtained for the 15 types of glass wool from measurement. Coefficients and degrees are shown as a function of airflow resistivity in Figs. 2 and 3, respectively. Note that most of them, e.g., $c, p, b, d$ and $q$, strongly depend on airflow resistivity. This dependence suggests that the formula structure based on Eqs. (3)-(6) essentially contains a source of error.

Further, the actual $R, X, \alpha$ and $\beta$ values for the 15 types of glass wool and 9 types of rock wool obtained from measurement are compared with predicted values. The actual values in terms of $R / \rho_{0} c_{0}-1,-X / \rho_{0} c_{0}, c_{0} \alpha / \omega$ and $c_{0} \beta / \omega-1$, together with predicted values from the Delany-Bazley model are shown in Fig. 4 as a function of $f / \sigma$. Clearly erroneous data due to resonance and the dip phenomena are excluded from the data. A similar comparison with the Miki model is shown in Fig. 5. Both the predicted values are very close to the actual values at $f / \sigma \cong 0.05 \mathrm{~m}^{3} / \mathrm{kg}$; however, they diverge from the actual values as $f / \sigma$ becomes further from $0.05 \mathrm{~m}^{3} / \mathrm{kg}$. In Figs. 4 
Table 3 Thickness, bulk density and measured airflow resistivity of the samples.

\begin{tabular}{lccc}
\hline & $\begin{array}{c}\text { Thickness } \\
{[\mathrm{mm}]}\end{array}$ & $\begin{array}{c}\text { Bulk } \\
\text { density } \\
{\left[\mathrm{kg} / \mathrm{m}^{3}\right]}\end{array}$ & $\begin{array}{r}\text { Airflow } \\
\text { resistivity } \\
{\left[\mathrm{Pa} \cdot \mathrm{s} / \mathrm{m}^{2}\right]}\end{array}$ \\
\hline galss wool 01 & 52.5 & 20.0 & 6,000 \\
galss wool 02 & 53.5 & 20.2 & 6,600 \\
galss wool 03 & 54.0 & 22.2 & 6,900 \\
galss wool 04 & 25.0 & 28.0 & 12,300 \\
galss wool 05 & 25.0 & 32.2 & 13,600 \\
galss wool 06 & 25.0 & 33.8 & 16,500 \\
galss wool 07 & 26.0 & 37.9 & 17,800 \\
galss wool 08 & 52.0 & 43.6 & 18,600 \\
galss wool 09 & 52.0 & 47.2 & 19,100 \\
galss wool 10 & 10.0 & 81.2 & 44,600 \\
galss wool 11 & 26.5 & 90.9 & 53,100 \\
galss wool 12 & 27.0 & 87.8 & 54,600 \\
galss wool 13 & 27.0 & 85.1 & 55,200 \\
galss wool 14 & 8.0 & 102.3 & 63,900 \\
galss wool 15 & 8.0 & 102.4 & 72,900 \\
\hline rock wool 01 & 35.0 & 29.7 & 10,100 \\
rock wool 02 & 30.0 & 32.1 & 13,500 \\
rock wool 03 & 43.0 & 38.4 & 15,100 \\
rock wool 04 & 35.0 & 40.2 & 15,600 \\
rock wool 05 & 27.0 & 42.8 & 21,600 \\
rock wool 06 & 28.0 & 46.2 & 25,100 \\
rock wool 07 & 21.0 & 78.4 & 46,000 \\
rock wool 08 & 25.0 & 88.4 & 63,400 \\
rock wool 09 & 24.0 & 97.0 & 69,400 \\
\hline
\end{tabular}

and 5, the actual values form a gradual curve; on the other hand, the predicted values form a straight line on the logarithmic chart, which results in the prediction error. It is clear, as mentioned above, that the coefficients and degrees are not constants but variables that depend on the airflow resistivity.

Therefore, the basic Delany-Bazley and Miki models are discussed in the following section, and an easy-tohandle prediction model that differs from Eqs. (3)-(6) in its formula structure is derived.

\subsection{Basic Model}

The basic sound-absorbing properties of a fibrous material can be explained by capillary theory. This theory forms the basis of many prediction expressions $[1,2,9]$. Both the porosity and the tortuosity are considered to be unity; therefore, characteristic impedance $Z_{\mathrm{c}}$ and propagation constant $\gamma$ are given by the following equations.

$$
\begin{aligned}
& Z_{\mathrm{c}}=\rho_{0} c_{0} \sqrt{1+\frac{\sigma}{j \omega \rho_{0}}} \\
& \gamma=\frac{j \omega}{c_{0}} \sqrt{1+\frac{\sigma}{j \omega \rho_{0}}}
\end{aligned}
$$

Equations (7) and (8) are temporarily called the basic model in this paper. When this model is expanded, the real

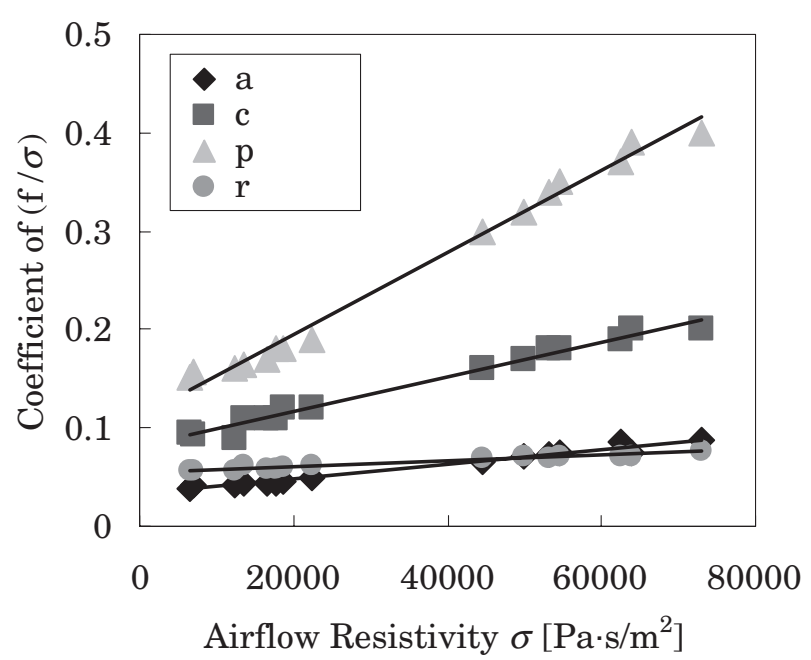

Fig. 2 Relation between airflow resistivity and coefficients of $(f / \sigma)$.

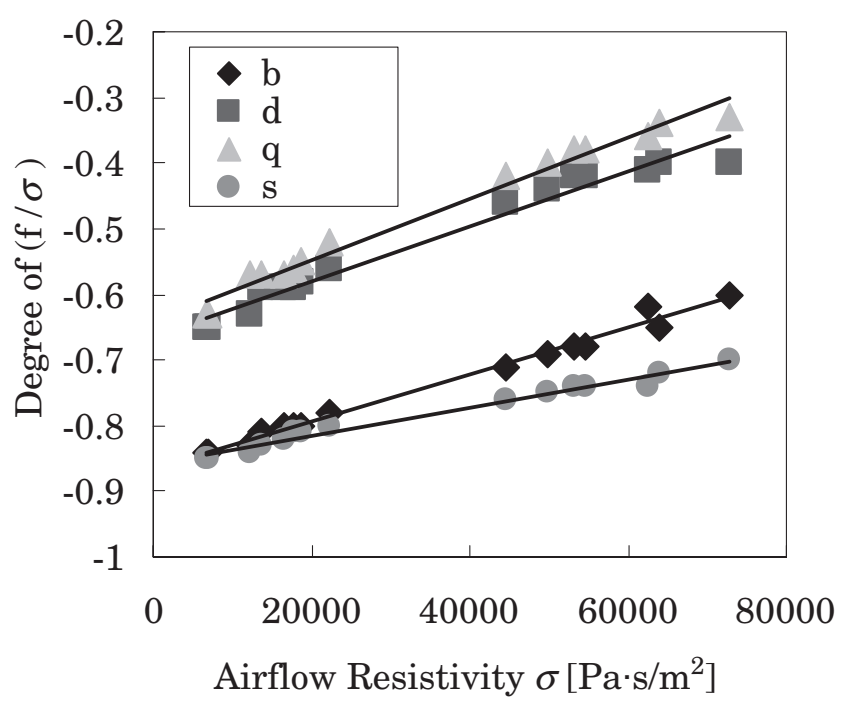

Fig. 3 Relation between airflow resistivity and degrees of $(f / \sigma)$.

and imaginary parts, corresponding to those in Eqs. (1) and (2), are obtained as follows.

$$
\begin{aligned}
& R=\rho_{0} c_{0} \sqrt{\frac{1}{2}\left\{\sqrt{1+\left(\frac{\sigma}{\omega \rho_{0}}\right)^{2}}+1\right\}} \\
& X=-\rho_{0} c_{0} \sqrt{\frac{1}{2}\left\{\sqrt{1+\left(\frac{\sigma}{\omega \rho_{0}}\right)^{2}}-1\right\}} \\
& \alpha=\frac{\omega}{c_{0}} \sqrt{\frac{1}{2}\left\{\sqrt{1+\left(\frac{\sigma}{\omega \rho_{0}}\right)^{2}-1}\right\}} \\
& \beta=\frac{\omega}{c_{0}} \sqrt{\frac{1}{2}\left\{\sqrt{1+\left(\frac{\sigma}{\omega \rho_{0}}\right)^{2}}+1\right\}}
\end{aligned}
$$



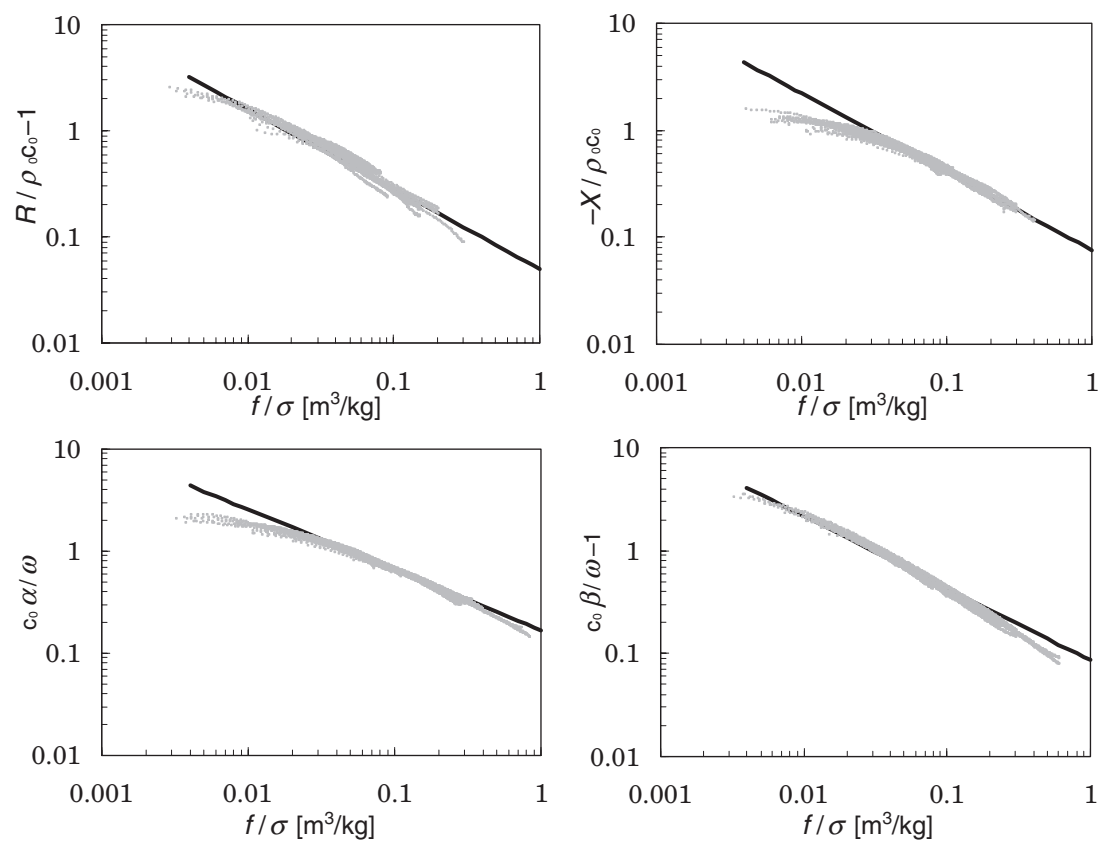

Fig. 4 Comparison between actual and predicted acoustical properties. Dots show the measured data. Straight lines show the predictions from the Delany-Bazley model.
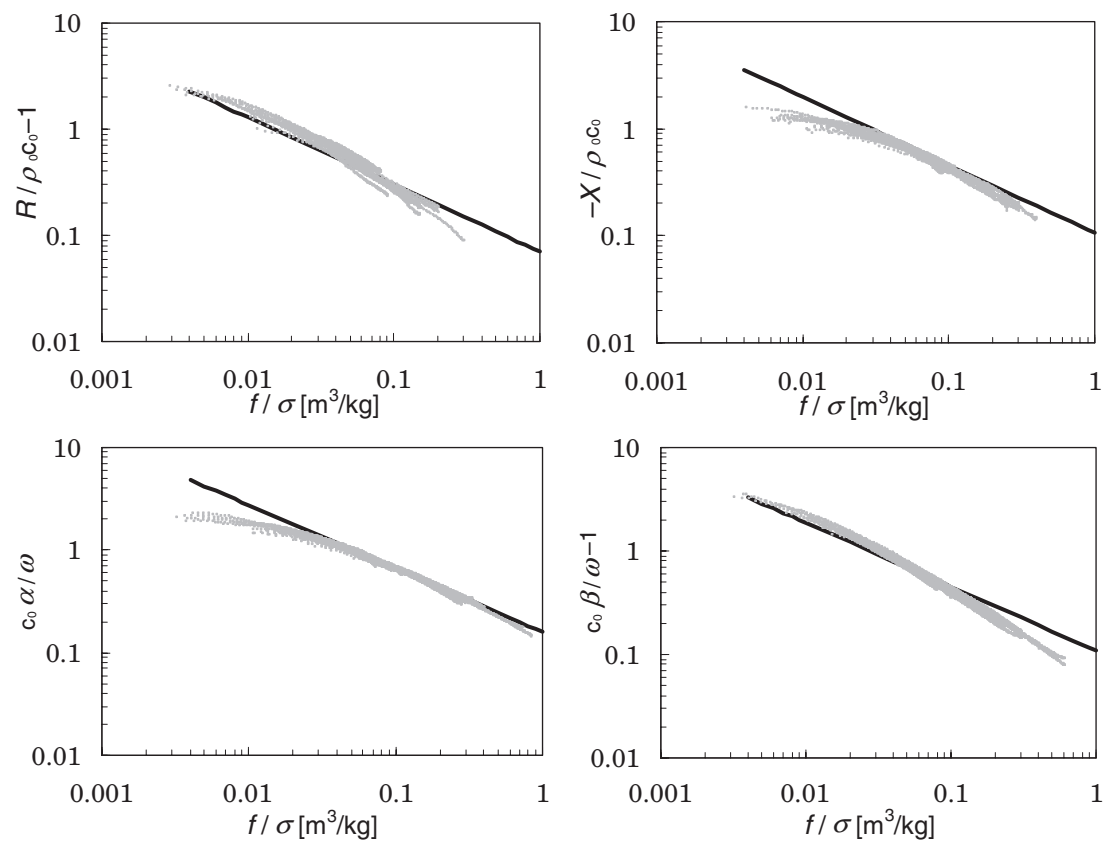

Fig. 5 Comparison between actual and predicted acoustical properties. Dots show the measured data. Straight lines show the predictions from the Miki model.

Note that the expression in side the outer root of Eq. (9) is the same as that of Eq. (12), and those of Eqs. (10) and (11) are also the same. In other words, $R$ and $\beta$ as well as $X$ and $\alpha$ both have the same relationship with airflow resistivity $(\sigma)$ and frequency $(f=\omega / 2 \pi)$. The modified values, $R / \rho_{0} c_{0}-1,-X / \rho_{0} c_{0}, c_{0} \alpha / \omega$ and $c_{0} \beta / \omega-1$ as functions of $f / \sigma$ are shown in Fig. 6.
These graphs are not linear but are curved lines. The slopes of $R$ and $\beta$ are almost the same, as are those of $X$ and $\alpha$, and the former are steeper than the latter. This tendency is the same as the actual data curves in Figs. 4 and 5. However, the actual curves are more gradual than those of the basic model.

An approximation was used to expand the basic 

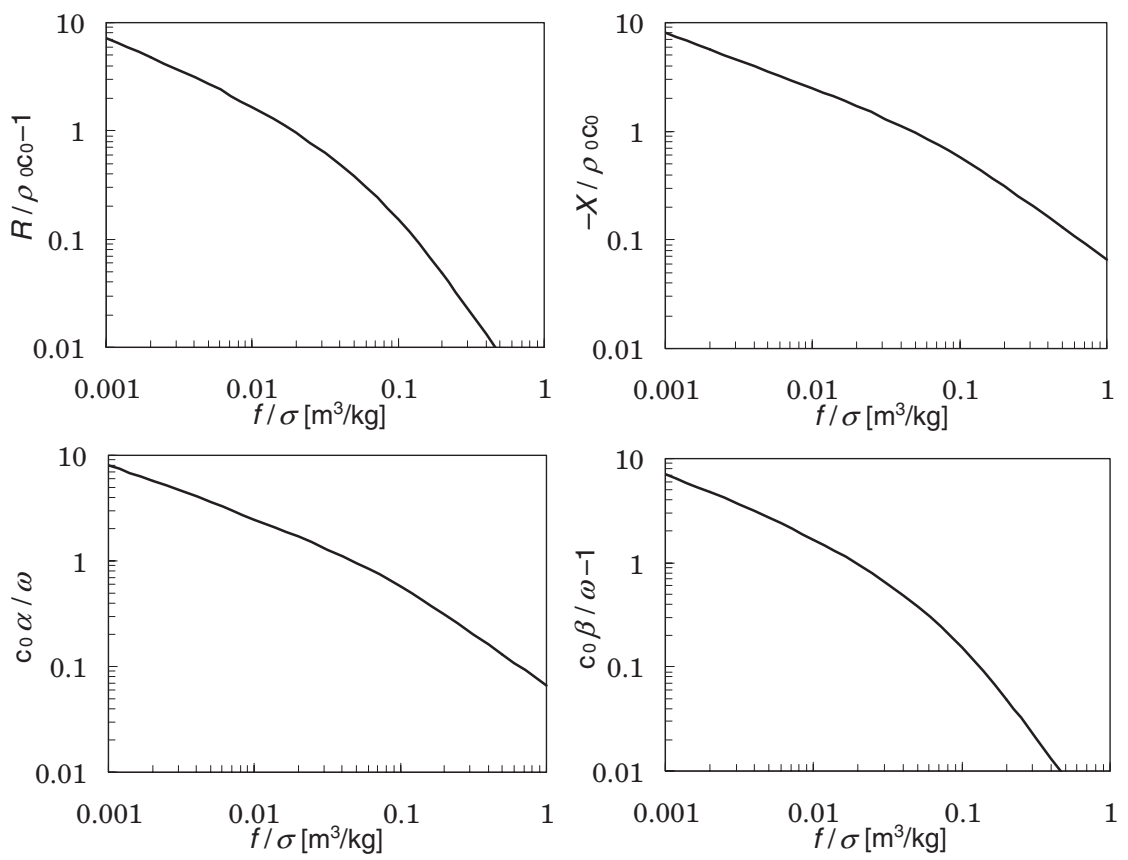

Fig. 6 Predicted acoustical properties based on the basic model.

models simply [9]. Delany and Bazley adjusted the slopes using the approximation of Eq. (13), which made the results of the prediction model near to the measured data [1].

$$
\sqrt{1+\frac{1}{j x}} \cong 1+k x^{l}+j m x^{n}
$$

Here, $x=\omega \rho_{0} / \sigma . k, l, m$ and $n$ are arbitrary variables used to fit the measured data.

The right side of Eq. (13) is a first-order approximation of the left side. The variables were chosen as follows: $k=0.125, l=-2, m=-0.5$ and $n=-1$. This model is only a good approximation when $1 / x$ is close to zero. On the left side of the equation, both the real part and the imaginary part can be used to draw curves as functions of $x$ on a logarithmic chart. However, on the right side, both parts form straight lines.

On the other hand, Miki assumed the approximation of Eq. (14) [2].

$$
\begin{aligned}
\sqrt{1+\frac{1}{j x}} & \cong 1+k^{\prime}(j x)^{l^{\prime}} \\
& =1+k^{\prime} \cos \frac{l^{\prime} \pi}{2} x^{l^{\prime}}+j k^{\prime} \sin \frac{l^{\prime} \pi}{2} x^{l^{\prime}}
\end{aligned}
$$

Here, $x=\omega \rho_{0} / \sigma \cdot k^{\prime}$ and $l^{\prime}$ are arbitrary variables used to fit the measured data.

After this approximation, the coefficients and degrees were determined by applying a Hilbert transform to satisfy the positive-real property. As shown on the right side of Eq. (14), the degrees of $x$ for the real and imaginary parts are the same, which results in the lines of the real and imaginary parts $\left(R / \rho_{0} c_{0}-1\right.$ and $-X / \rho_{0} c_{0}, c_{0} \alpha / \omega$ and $\left.c_{0} \beta / \omega-1\right)$ in Fig. 5 having the same slopes. Therefore, this approximation is only effective in the vicinity of $x=0$.

\subsection{New Model}

It is appropriate that the prediction model is not a straight line but a curve from both the theory and the measurement. The slopes of $R$ and $\beta$ are the same, and those of $X$ and $\alpha$ are the same, and the former are steeper. The real part of the characteristic impedance, $R$, approaches the impedance of air as $f / \sigma$ increases. The imaginary part of the propagation constant, $\beta$, similarly approaches the phase of air. However, the actual tendency from the measured results is more gradual than the predicted results using the basic model; the former do not change as rapidly as the latter. The improvement of the basic model to match the actual tendency may be possible by replacing the square roots in Eqs. (7) and (8) with slightly smaller degrees, however, the expressions become more complicated and difficult to handle. As an alternative method, it was found that simple expressions that include the common logarithm can be used to draw curves close to that formed by the measured results. The expressions used in our new model are as follows:

$$
\begin{aligned}
& R=\rho_{0} c_{0}\left\{1+0.00027\left(2-\log \frac{f}{\sigma}\right)^{6.2}\right\} \\
& X=-\rho_{0} c_{0}\left\{0.0047\left(2-\log \frac{f}{\sigma}\right)^{4.1}\right\}
\end{aligned}
$$



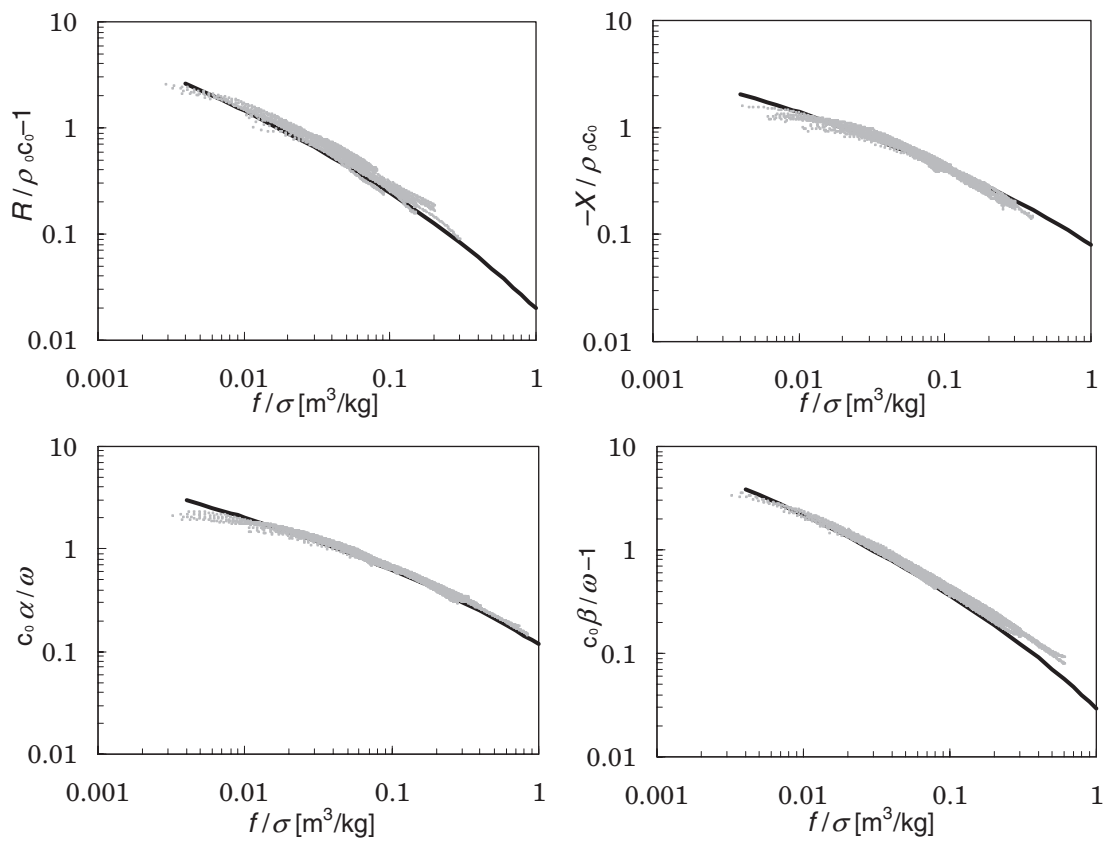

Fig. 7 Comparison between actual and predicted acoustical properties. Dots show the measured data. Curve lines show the predictions from the new model.

$$
\begin{aligned}
& \alpha=0.0069 \frac{\omega}{c_{0}}\left(2-\log \frac{f}{\sigma}\right)^{4.1} \\
& \beta=\frac{\omega}{c_{0}}\left\{1+0.0004\left(2-\log \frac{f}{\sigma}\right)^{6.2}\right\}
\end{aligned}
$$

This model was empirically derived. We found that the curve formed by the actual data was well simulated by the expression $a^{\prime}(2-\log (f / \sigma))^{b^{\prime}}$, where $a^{\prime}$ and $b^{\prime}$ are constants. The degree, $b^{\prime}$, determines the slope of the curve. The coefficient, $a^{\prime}$, determines the vertical position of the curve. In Eqs. (15)-(18), which were obtained through empirical fitting, the ratio of the coefficients in the real and imaginary parts with the same degrees used for determining $\gamma$ to those used for determining $Z_{\mathrm{c}}$ is about 1.47; that is, $0.0004 / 0.00027$ and $0.0069 / 0.0047$, respectively. This ratio is thought to be closely related to the porosity, the tortuosity and the pore shape factor ratio [9-11]. However, no further explanation can yet be given.

The predictions using the new model are shown in Fig. 7 together with the measured data. The predictions are much closer to the measured data over a wide $f / \sigma$ range.

Here, the measured data for two samples are compared with the predicted values from the three models. For a sample of glass wool with a low airflow resistivity (53.5 $\mathrm{mm}$ thickness, $20.2 \mathrm{~kg} / \mathrm{m}^{3}$ bulk density, $6,600 \mathrm{~Pa} \cdot \mathrm{s} /$ $\mathrm{m}^{2}$ airflow resistivity), the acoustical properties are shown in Figs. 8 and 9, and the normal incident sound absorption coefficients are shown in Fig. 10. For a sample of glass wool with a high airflow resistivity $(26.5 \mathrm{~mm}$ thickness,
$90.9 \mathrm{~kg} / \mathrm{m}^{3}$ bulk density, 53,100 $\mathrm{Pa} \cdot \mathrm{s} / \mathrm{m}^{2}$ airflow resistivity), the acoustical properties are shown in Figs. 11 and 12, and the normal incident sound absorption coefficients are shown in Fig. 13.

It is clear that the prediction errors of the characteristic impedance and propagation constant in the prediction models of the Delany-Bazley and Miki models increase the error of the sound absorption coefficients. In a sample with a low or high airflow resistivity, the error is large. The new model is very effective for prediction, because the error margins of the characteristic impedance and propagation constant are small.

\section{CONCLUDING REMARKS}

The expressions of the Delany-Bazley and Miki models, which predict the acoustical properties of porous materials from the airflow resistivity, were examined from the measurement of glass wool and rock wool. As a result, I proposed a new prediction model based on the measurement data. The new model can be used to predict the acoustical properties of a fibrous material with high accuracy compared with the Delany-Bazley and Miki models. The new model is particularly effective when $f / \sigma<0.01 \mathrm{~m}^{3} / \mathrm{kg}$ or $f / \sigma>0.1 \mathrm{~m}^{3} / \mathrm{kg}$. In the future, I expect that this new model will be used for the development and quality control of sound-absorbing materials.

\section{ACKKNOWLEDGMENTS}

I wish to express my gratitude to a number of my colleagues, particularly to the acoustical materials project 

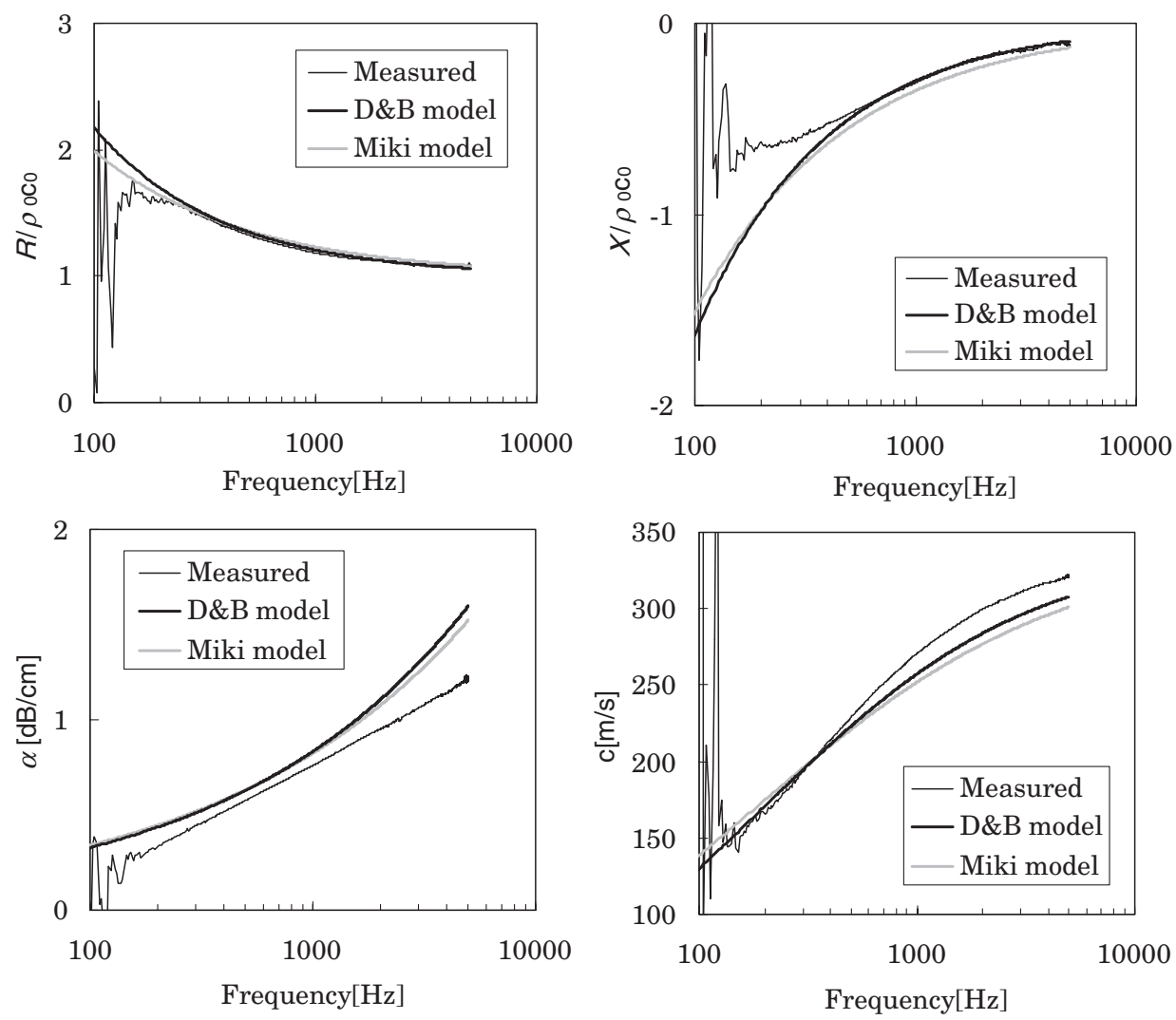

Fig. 8 Comparison between actual and predicted acoustical properties of glass wool with $53.5 \mathrm{~mm}$ thickness, $20.2 \mathrm{~kg} / \mathrm{m}^{3}$ bulk density and $6600 \mathrm{~Pa} \cdot \mathrm{s} / \mathrm{m}^{2}$ airflow resistivity. Dark lines show the prediction from the Delany-Bazley model. Pale lines show the predictions from the Miki model.
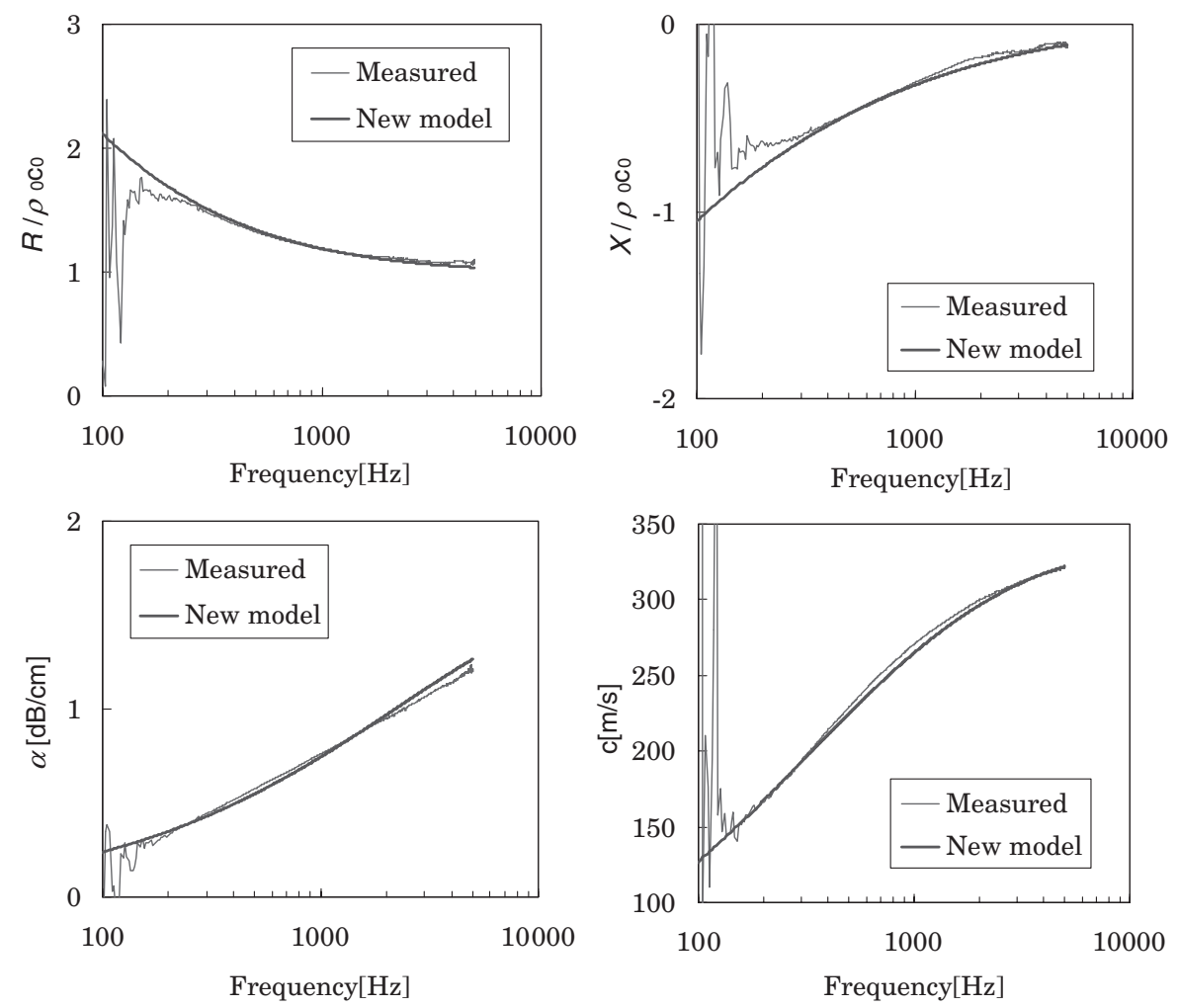

Fig. 9 Comparison between actual and predicted acoustical properties of glass wool with $53.5 \mathrm{~mm}$ thickness, $20.2 \mathrm{~kg} / \mathrm{m}^{3}$ bulk density and $6,600 \mathrm{~Pa} \cdot \mathrm{s} / \mathrm{m}^{2}$ airflow resistivity. Dark lines show the predictions from the new model. 

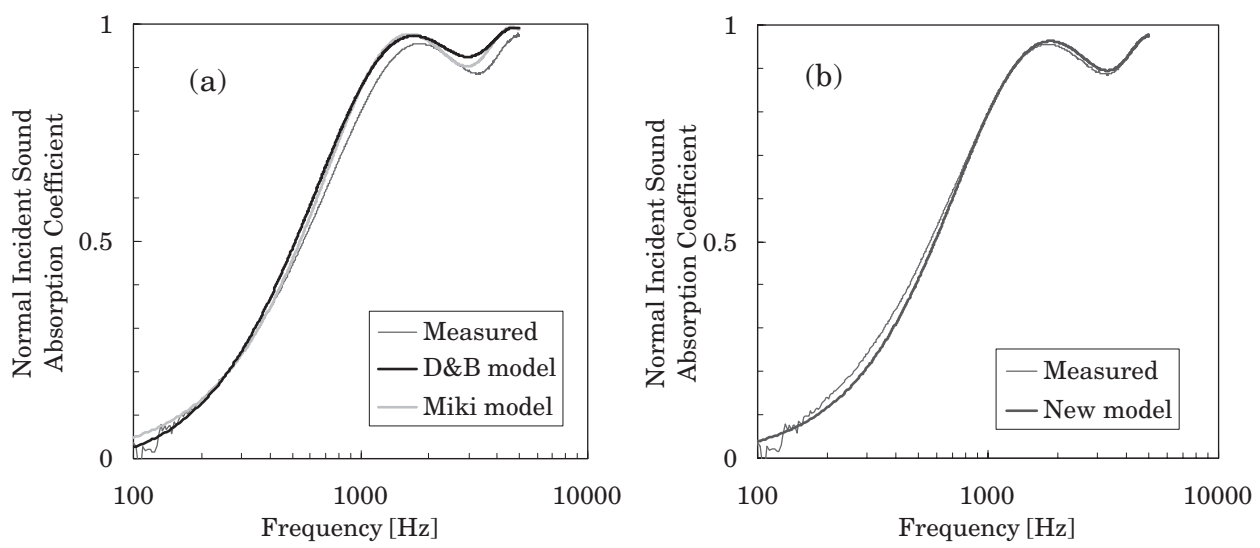

Fig. 10 Comparison between actual and predicted normal incident sound absorption coefficient of glass wool with $53.5 \mathrm{~mm}$ thickness, $20.2 \mathrm{~kg} / \mathrm{m}^{3}$ bulk density and $6,600 \mathrm{~Pa} \cdot \mathrm{s} / \mathrm{m}^{2}$ airflow resistivity. (a) The dark line shows the prediction from the Delany-Bazley model. The pale line shows the prediction from the Miki model. (b) The dark line shows the prediction from the new model.
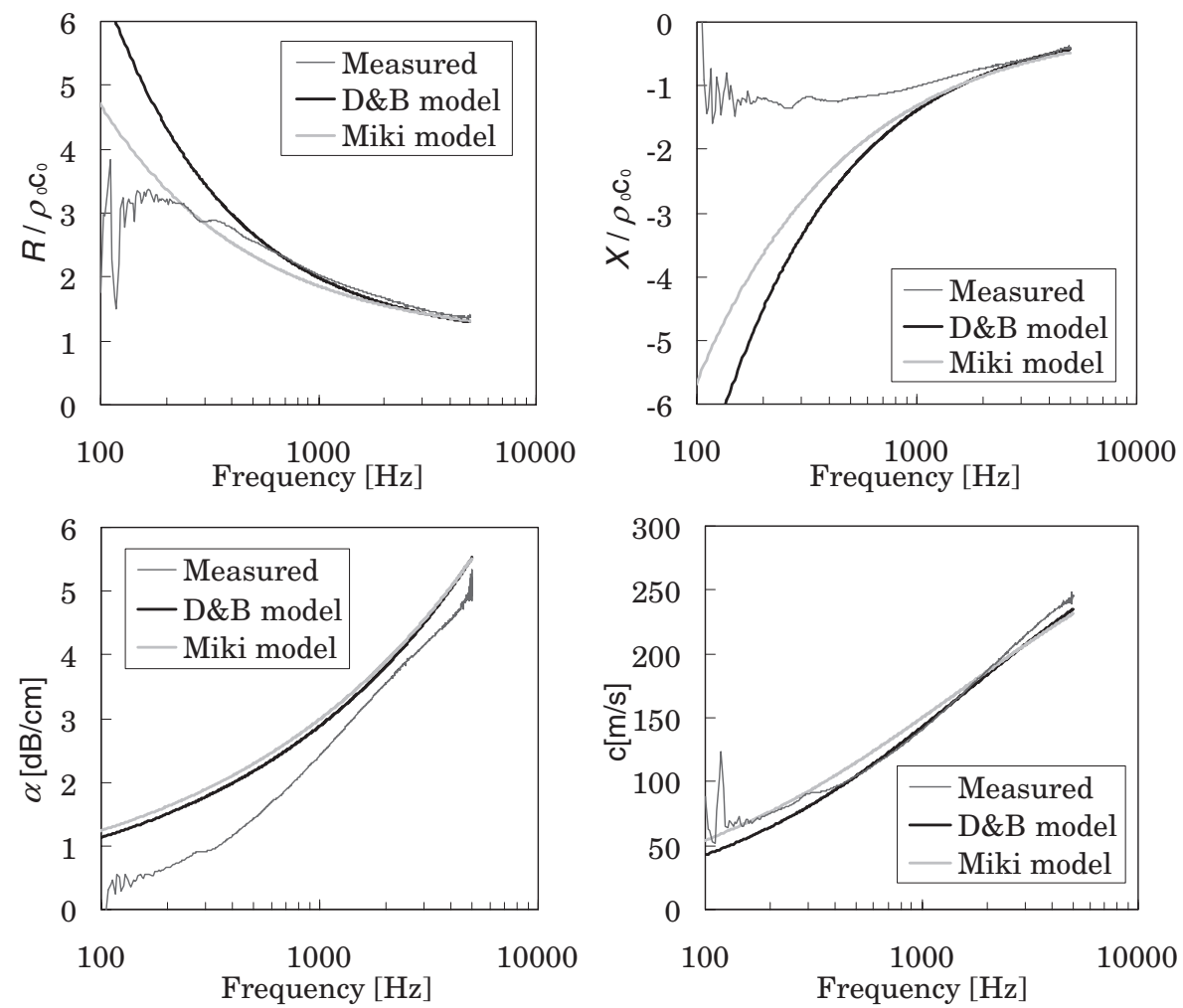

Fig. 11 Comparison between actual and predicted acoustical properties of glass wool with $26.5 \mathrm{~mm}$ thickness, $90.9 \mathrm{~kg} / \mathrm{m}^{3}$ bulk density and $53,100 \mathrm{~Pa} \cdot \mathrm{s} / \mathrm{m}^{2}$ airflow resistivity. Dark lines show the prediction from the Delany-Bazley model. Pale lines show the predictions from the Miki model.

leader, Mr. N. Kino for valuable comments and criticism, the project member, Mr. T. Ueno for verifying the new model and Dr. O. Sugiyama for reading the entire manuscript and giving valuable advice.

\section{REFERENCES}

[1] M. E. Delany and E. N. Bazley, "Acoustical properties of fibrous absorbent materials," Appl. Acoust., 3, 105-116 (1970).

[2] Y. Miki, "Acoustical properties of porous materials -
Modifications of Delany-Bazley models —," J. Acoust. Soc. Jpn. (E), 11, 19-24 (1990).

[3] Y. Takahashi, T. Otsuru and R. Tomiku, "In situ measurements of absorption characteristics using two microphones and environmental 'anonymous' noise," Acoust. Sci. \& Tech., 24, 382-385 (2003).

[4] Y. W. Lam, "Issues for computer modeling of room acoustics in non-concert hall settings," Acoust. Sci. \& Tech., 26, 145155 (2005).

[5] S. Sugie, J. Yoshimura and H. Ogawa, "Absorption character- 

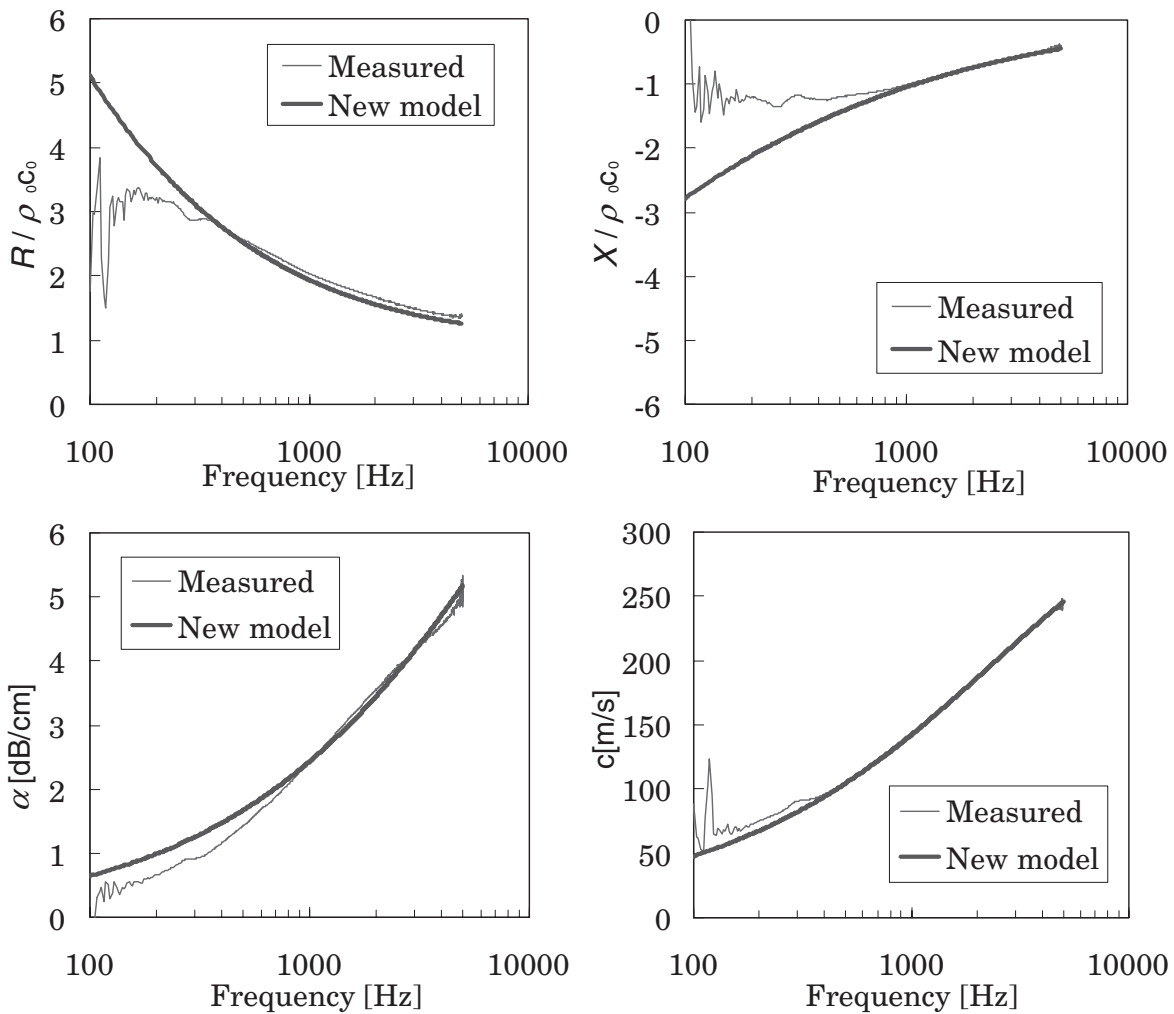

Fig. 12 Comparison between actual and predicted acoustical properties of glass wool with $26.5 \mathrm{~mm}$ thickness, $90.9 \mathrm{~kg} / \mathrm{m}^{3}$ bulk density and $53,100 \mathrm{~Pa} \cdot \mathrm{s} / \mathrm{m}^{2}$ airflow resistivity. Dark lines show the predictions from the new model.
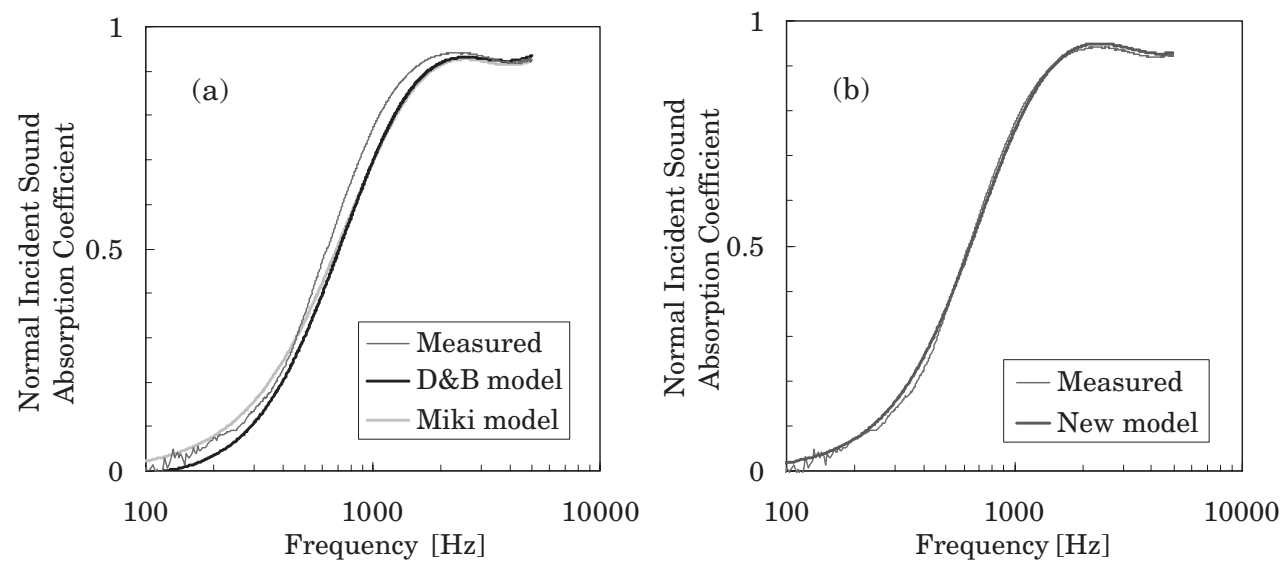

Fig. 13 Comparison between actual and predicted normal incident sound absorption coefficient of glass wool with $26.5 \mathrm{~mm}$ thickness, $90.9 \mathrm{~kg} / \mathrm{m}^{3}$ bulk density and $53,100 \mathrm{~Pa} \cdot \mathrm{s} / \mathrm{m}^{2}$ airflow resistivity. (a) The dark line shows the prediction from the Delany-Bazley model. The pale line shows the prediction from the Miki model. (b) The dark line shows the prediction from the new model.

istics of fibrous material covered with perforated facing and film,” Acoust. Sci. \& Tech., 27, 87-96 (2006).

[6] H. Utsuno, T. Tanaka and T. Fujikawa, "Transfer function method for measuring characteristic impedance and propagation constant of porous materials," J. Acoust. Soc. Am., 86, 637-643 (1989).

[7] ISO 10534-2, "Acoustics - Determination of sound absorption coefficient and impedance in impedance tubes - Part 2: Transfer-function method" (1998).

[8] ISO 9053, "Acoustics — Materials for acoustical applications
— Determination of airflow resistance" (1991).

[9] C. Zwiker and C. W. Kosten, Sound Absorbing Materials (Elsevier, New York, 1949).

[10] Y. Miki, "Acoustical properties of porous materials - Generalizations of empirical models —," J. Acoust. Soc. Jpn. (E), 11, 25-28 (1990).

[11] K. Attenborough, "Acoustical characteristics of rigid fibrous absorbents and granular materials," J. Acoust. Soc. Am., 73, 785-799 (1983). 